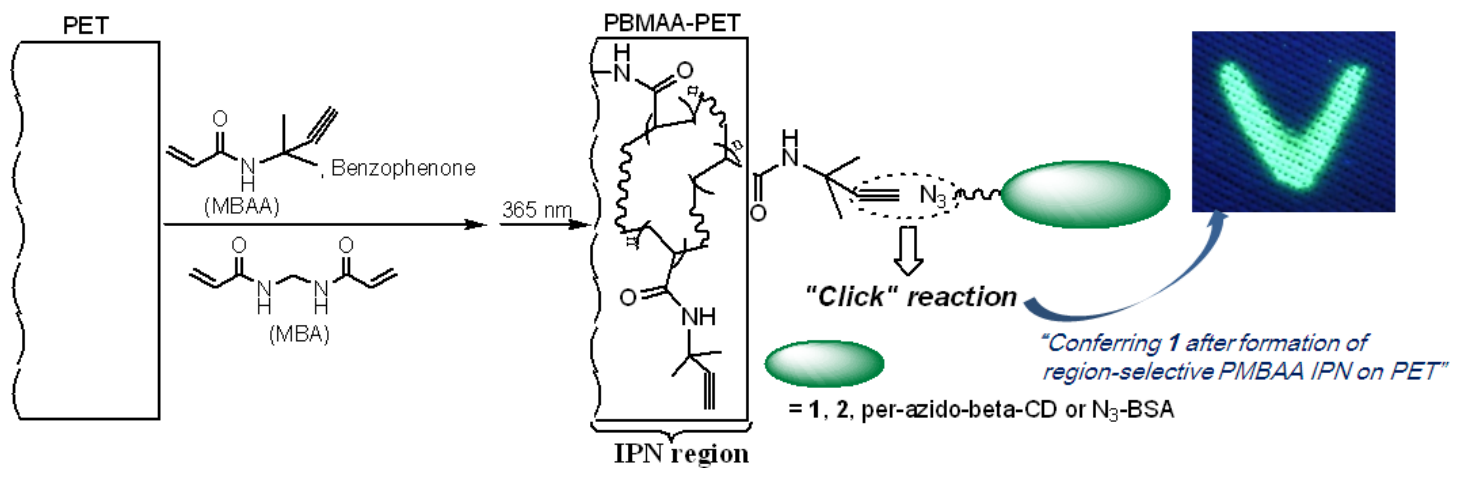




\title{
Versatile surface biofunctionalization of poly(ethylene terephthalate) by interpenetrating polymerization of a butynyl monomer followed by "Click Chemistry"
}

\author{
Lingdong Li, Nan Zhao, Song Liu* \\ Department of Textile Sciences, Faculty of Human Ecology, University of Manitoba, Winnipeg, Manitoba, Canada R3T 2N2
}

\section{A R T I C L E I N F O}

\section{Article history:}

Received 16 September 2011

Received in revised form

15 November 2011

Accepted 19 November 2011

Available online 27 November 2011

\section{Keywords:}

Interpenetrating polymer network

Surface biofunctionalization

Antibacterial activity

\begin{abstract}
A B S T R A C T
Biofunctionalization of poly(ethylene terephthalate) (PET) is crucial to its medical and biomedical applications such as surgical drapes, vascular grafts and ligament prostheses. To furnish PET with an alkynyl handle, N-(2-methylbut-3-yn-2-yl)acrylamide (MBAA) underwent photo-initiated copolymerization with $\mathrm{N} \mathrm{N}^{\prime}$-methylenebisacrylamide (MBA) in methanol-swollen PET surface to form a 3dimensional interpenetrating network (IPN). The alkynyl handle terminated surface was denoted as PMBAA-PET. A region-selective modification could be achieved using an engraved mask during the photo-initiated copolymerization. Several functional azides including dansyl-azide 1, azido-5,5dimethyl-hydantoin analog 2 , per-azido- $\beta$-cyclodextrin (per-azido- $\beta$-CD) and azido-Bovine Serum Albumin (BSA- $\mathrm{N}_{3}$ ), were successfully bonded onto PMBAA-PET surface via Huisgen 1,3-dipolar cycloaddition. Kinetic study of the heterogeneous "click" reaction between PMBAA-PET and $\mathbf{1}$ was investigated using X-ray photoelectron spectroscopy (XPS) and elemental analysis. PMBAA-PET was rendered with effective biocidal activity against a healthcare-associated methicilin-resistant Staphylococcus aureus (HAMRSA) and a multi-drug-resistant Escherichia coli (MDR-E. coli) after 2 was conferred. Meanwhile, accessible $\mathrm{CD}$ cavity was determined and the amount of covalently immobilized BSA protein was also quantified after the respective "click" linkages of per-azido- $\beta-C D$ and BSA- $\mathrm{N}_{3}$ on PMBAA-PET surface were established.
\end{abstract}

(c) 2011 Elsevier Ltd. All rights reserved.

\section{Introduction}

Biofunctionalization of poly(ethylene terephthalate) (PET) substrates to allow for specific interactions with biological targets is important for the development of PET-based surgical drapes, implantable sutures [1], surgical meshes [2], vascular grafts [3], sewing cuffs for heart valves [4] and ligaments [5]. Generally, a coating method was used to deposit functional moieties onto the chemically inert PET substrate which is known to possess desirable mechanical strength and biological durability [6]. However, the coating is potentially unstable and may be readily removed from the substrate. It is often desirable to achieve stable linkage by covalently linking functional moieties onto PET. To this end, a radical grafting polymerization technique has been researched widely since long functional polymer chains can be easily grafted once a reactive species is generated on the substrate surface. However, introducing reactive species onto the chemically inert

\footnotetext{
* Corresponding author. Tel.: +1 204474 9616; fax: +1 2044747593.

E-mail address: lius0@cc.umanitoba.ca (S. Liu).
}

PET substrate usually entails high energy irradiation, harsh chemical hydrolysis/oxidation or lengthy reactions [7]. In order to graft poly(ethylene glycol)methyletheracrylate (PEGMA) brushes onto PET via surface-initiated atom transfer radical polymerization (ATRP), an ATRP initiator was first immobilized onto PET in several steps. A benzophenone derivative with hydroxyl group was first synthesized and anchored to the polymer surface by exposure to UV (365 nm) irradiation, and subsequently the immobilized hydroxyl group was reacted with bromoisobutyryl bromide to furnish the polymer surface with an ATRP initiator [8]. To introduce the biofunction of white blood cell adhesion onto PET fibers, Renaudie et al. [9] prepared a lactose derivative that carries a photoreactive acryl azide group. Upon UV photolysis (260 nm), the acryl azide group can generate highly reactive phenylnitrene which could insert into $\mathrm{C}-\mathrm{H}$ and $\mathrm{N}-\mathrm{H}$ bonds creating a covalent bond on the PET substrate. Phenylnitrene is highly reactive but not selective in binding, leading to the formation of polymeric multilayers of grafted lactose and an altered structure of this immobilized functional molecule, suggesting the possibly compromised relevant biofunctions. 
Recently, the formation of surface interpenetrating network (IPN) polymers as a means of surface modification has attracted much attention as an alternative to chemical grafting [10-13]. We reported a new technique in immobilizing functional polymers onto the surfaces of chemically inert semicrystalline thermoplastic polymeric substrates [11-13]. A functional monomer together with a crosslinker was co-polymerized in the swollen surfaces of PET to form a 3-D interlocking structure which was durably immobilized on the surface of PET. This type of IPN is defined as a thermoplastic semi-IPN and the surface modification produced by this technique is durable except when the substrate polymer is dissolved or melted which will not happen in most applications [11]. This technique has been proven to be effective in surface modification of many semicrystalline polymers including PET [11] and polypropylene (PP) [13]. Not every functional monomer, however, can easily polymerize in swollen PET or PP to form an interpenetrating network. For example, 3-allyl-5,5-dimethylhydantoin (ADMH), a good precursor of biocidal N-halamine, has been successfully grafted onto various fabric surfaces to introduce potent antibacterial function [14,15]. But due to its property of self-inhibited polymerization, ADMH cannot polymerize effectively to reach the high molecular weight required to form an interpenetrating network. It is hypothesized that a universal handle, such as an alkynyl or azido group, can be first generated onto PET surfaces using the IPN approach. Following that, a variety of bio-functions can be introduced easily by the robust and effective "click" reaction.

"Click Chemistry" [16], especially the $\mathrm{Cu}(\mathrm{I})$-catalyzed azidealkyne cycloaddition (CuAAC, usually termed as "click"), is an extraordinarily powerful strategy for the synthesis of pharmaceutical libraries [17], derivatization of cellular surfaces [18] and preparation of functional polymers [19] because of its reaction specificity, quantitative yields, and good functional group tolerance. Several current reviews address the development and modification of polymers using "Click Chemistry" [20,21].

Our approach to the immobilization of alkynyl-presenting ("clickable") handles on PET is based on the technique of forming an interpenetrating network on the surface of this semicrystalline thermoplastic polymer. The monomer $\mathrm{N}-(2-$ methylbut-3-yn-2-yl)acrylamide (MBAA in Scheme 1) was synthesized [22] and co-polymerized with N,N'-methylenebisacrylamide (MBA, crosslinker) in the swollen surface of PET to form IPN, leading to a PET substrate bearing alkynyl groups (named as PMBAA-PET). The introduced alkynyl handles on PET surface are expected to be implicated in "click" reactions and to realize versatile functional modifications of PET matrix (Scheme 2). A dyansyl-azide agent ( $\mathbf{1}$ in Scheme 1) was prepared and "clicked" onto the alkynyl-terminated PET material, confirming a uniform distribution of the alkyne handles on PMBAA-PET. Several other azide molecules including azido-5,5-dimethylhydantoin analogs ( 2 in Scheme 1 ), per-azido- $\beta$-cyclodextrin (perazido- $\beta$-CD in Scheme 1 ) and azido-Bovine Serum Albumin (BSA$\mathrm{N}_{3}$ ), were prepared and successfully "clicked" onto PMBAA-PET to introduce various bio-functions.

\section{Experimental}

\subsection{Materials}

Poly(ethylene terephthalate) (PET) plain woven fabric $(\# 777 \mathrm{H})$ was purchased from Testfabrics, Inc. All solvents and chemicals such as 5,5-dimethyhydantoin, cyclohexylamine, benzophenone (BP), N, $\mathrm{N}^{\prime}$-methylenebisacrylamide (MBA) and fluorescein isothiocyanate (FITC) were purchased from either Aldrich or Fisher and used without further purification unless otherwise noted.

A clinical isolate of healthcare-associated methicilin-resistant Staphylococcus aureus (HA-MRSA, isolate \#70527) and that of multi-drug-resistant Escherichia coli (MDR-E. coli, isolate \#70094) were obtained from the CANWARD study assessing antimicrobial resistance in Canadian hospitals, www.canr.ca.

Alkynyl monomer MBAA was synthesized following a published protocol [22]. Azido-compounds such as 1-azidohexanol, perazido- $\beta-C D$ and azidopentanoic acid-NHS were also prepared according to known procedures [23-25], and the obtained NMR data were identical to those found in literature. Purification of synthesized compounds was conducted by flash column chromatography on silica gel received from Selecto Scientific Georgia, USA.

\subsection{Surface modification of PET}

PET fabric (round swatch, diameter $=10.8 \mathrm{~cm}$ ) was first immersed in $20 \mathrm{~mL}$ methanol swelling solution of MBAA $\left(2 \mathrm{~mol} \mathrm{~L}^{-1}\right), \mathrm{MBA}\left(0.045 \mathrm{~mol} \mathrm{~L}^{-1}\right)$ and BP $\left(0.082 \mathrm{~mol} \mathrm{~L}^{-1}\right)$ at $40^{\circ} \mathrm{C}$ for $2 \mathrm{~h}$. Excess swelling solution was then dripped off and absorbed by filter paper from the specimen prior to UV irradiation (365 nm) for $2 \mathrm{~h}$. After the UV induced polymerization, the loosely attached polymer and the residual monomer were Soxhlet-extracted for $24 \mathrm{~h}$ with methanol. Finally, the modified PET sample was dried under vacuum overnight and stored in the desiccator for $48 \mathrm{~h}$ to reach a constant weight. The resultant modified fabric is referred to as poly(MBAA)-PET (PMBAA-PET).

The immobilization percentage (IP) was calculated as follows:

$\mathrm{IP}=\left(\mathrm{W}_{2}-\mathrm{W}_{1}\right) / \mathrm{W}_{1}$

where $W_{1}$ is the weight of pristine PET; $W_{2}$ is the weight of PMBAAPET.

Another piece of PET fabric was swollen in the same manner, and covered with an identical-sized piece of aluminum foil engraved with a letter "V" and a letter "I" during exposure to UV irradiation. Then the fabric was Soxhlet-extracted and dried as above. The obtained fabric with patterned modification is thus obtained.

\subsection{Instrumental analysis and characterization}

FTIR spectra were taken on a Nicolet iS10 spectrometer (Thermo Electron Corporation) using $\mathrm{KBr}$ pellets. NMR spectra were

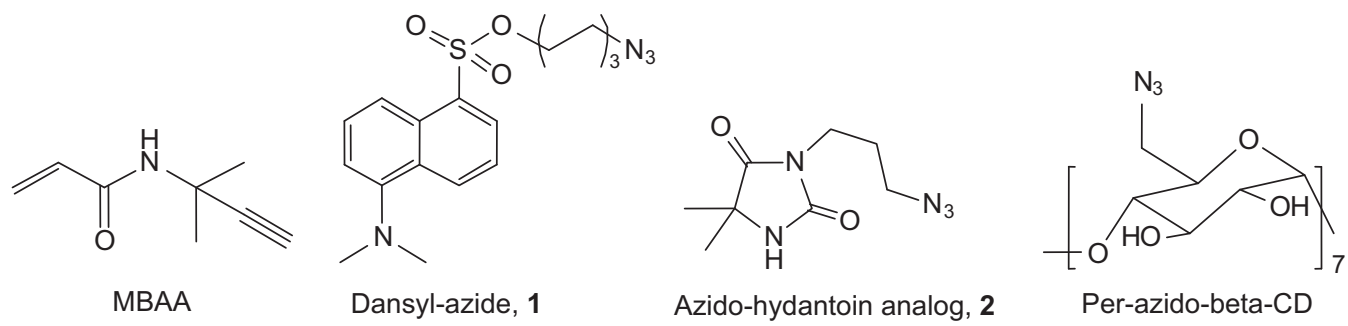

Scheme 1. Structures of alkynyl aonomer MBAA) and azido-compounds. 


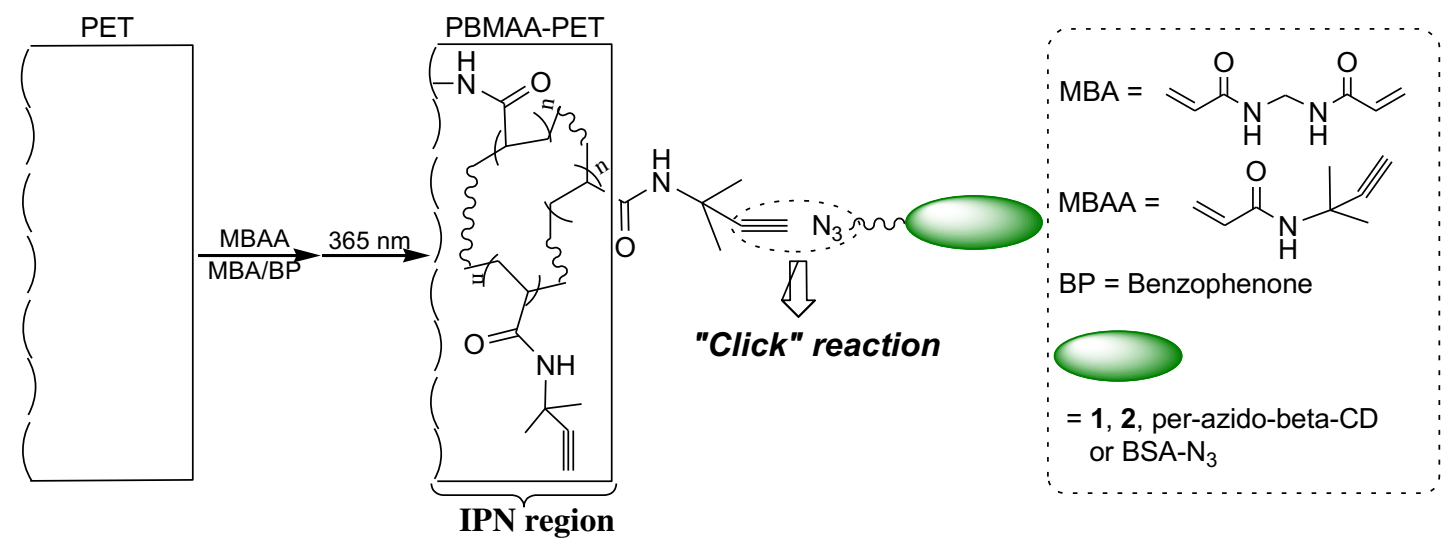

Scheme 2. Surface modification of PET by forming a thermoplastic semi-IPN with Poly-MBAA (PMBAA-PET) and direct "click" linkage with the specific azides.

recorded at room temperature in $5 \mathrm{~mm}$ NMR tubes on a Bruker Avance $300 \mathrm{MHz}$ NMR spectrometer. Accurate mass measurements were performed using a PerkinElmex Sciex prOTOFTM 2000 MALDIOTOF Mass Spectrometer. XPS data were acquired with a Kartos Axis Ultra spectrometer by Kratos Analytical, Inc. Fluorescence was observed under a Carl Zeiss microscope from Germany. Contact angle was measured by a standard contact angle goniometer (Model 200, with DROPimage standard) from Ramé-Hart Inc.

\subsection{Synthesis of dansyl-azide (1)}

To dansyl chloride ( $0.94 \mathrm{~g}, 3.5 \mathrm{mmol})$ solution in $\mathrm{CH}_{2} \mathrm{Cl}_{2}(12 \mathrm{~mL})$ and $0.5 \mathrm{~mL}$ pyridine was added excess 1 -azidohexanol $(0.57 \mathrm{~g}$, $4.0 \mathrm{~mol}$ ). The resulting solution was stirred for $24 \mathrm{~h}$ before being concentrated under vacuum. The residue was loaded on column and washed with EtOAc/Hex (1:8). The fluorescent fractions were combined to afford 2 as fluorescent oil (1.08 g, 83\%); NMR $\left(\mathrm{CDCl}_{3}\right.$, $300 \mathrm{MHz}) \delta 8.64(\mathrm{~d}, J=8.5 \mathrm{~Hz}, 1 \mathrm{H}), 8.29(\mathrm{~m}, 2 \mathrm{H}), 7.59(\mathrm{~m}, 2 \mathrm{H}), 7.24$ $(\mathrm{d}, J=7.6 \mathrm{~Hz}, 1 \mathrm{H}), 4.02(\mathrm{t}, J=6.3,2 \mathrm{H}), 3.14(\mathrm{t}, J=6.9 \mathrm{~Hz}, 2 \mathrm{H}), 2.92$ $(\mathrm{s}, 6 \mathrm{H}), 1.62(\mathrm{~m}, 2 \mathrm{H}), 1.44(\mathrm{~m}, 2 \mathrm{H}), 1.18-1.31(\mathrm{~m}, 4 \mathrm{H})$; HRMS (MALDI-TOF) calculated for $\mathrm{C}_{18} \mathrm{H}_{25} \mathrm{~N}_{4} \mathrm{O}_{3} \mathrm{~S}[\mathrm{M}+\mathrm{H}]^{+}$: 377.1647, found: 377.1646 .

\subsection{Synthesis of azido-hydantoin analog (2)}

To the 5,5-dimethyhydantoin (3.2 $\mathrm{g}, 25 \mathrm{mmol})$ solution in $\mathrm{Me}_{2} \mathrm{CO}(120 \mathrm{~mL})$ was added anhydrous $\mathrm{K}_{2} \mathrm{CO}_{3}(10 \mathrm{~g}$, $75 \mathrm{mmol})$. The resulting suspension was heated to gentle reflux for $0.5 \mathrm{~h}$ and then 1,3-dibromopropane ( $2.8 \mathrm{~mL}, 27 \mathrm{mmol}$ ) was added in one portion. The mixture was continued to reflux overnight and the hot reaction mixture was filtered off by passing through a thin layer of silica gel. The filtrate was evaporated to give a white solid which was further purified by column chromatography (EtOAc/Hexanes $=1 / 2-1 / 1)$ to afford bromide 3 as white solid (5.1 g, 82\%); ${ }^{1} \mathrm{H}$ NMR $\left(\mathrm{CDCl}_{3}\right.$, $300 \mathrm{MHz}) \delta 6.07(\mathrm{br}, 1 \mathrm{H}), 3.66(\mathrm{t}, J=6.9 \mathrm{~Hz}, 2 \mathrm{H}), 3.40(\mathrm{t}, J=6.6 \mathrm{~Hz})$, $2.22(\mathrm{~m}, 2 \mathrm{H}), 1.46(\mathrm{~s}, 6 \mathrm{H}) ;{ }^{13} \mathrm{C} \mathrm{NMR}\left(\mathrm{CDCl}_{3}, 75 \mathrm{MHz}\right) \delta 177.2,156.2$, 58.8, 37.4, 31.2, 29.6, 25.1; HRMS (MALDI-TOF) calculated for $\mathrm{C}_{8} \mathrm{H}_{14} \mathrm{BrN}_{2} \mathrm{O}_{2}[\mathrm{M}+\mathrm{H}]^{+}: 249.0238$, found: 249.0235 .

To the bromide 3 (2.4 g, $9.8 \mathrm{mmol})$ solution in DMF $(20 \mathrm{~mL})$ was added $\mathrm{NaN}_{3}(0.96 \mathrm{~g}, 14.7 \mathrm{mmol})$. The resulting suspension was heated to $80{ }^{\circ} \mathrm{C}$ and continuously stirred overnight. The cooled mixture was concentrated and the residue was partitioned between EtOAc and $\mathrm{H}_{2} \mathrm{O}$. The organic layer was concentrated again to give the crude compound which was further purified by column chromatography (EtOAc/Hexanes $=1 / 2-1 / 1$ ) to afford 2 as colorless viscous oil (1.8 g, 90\%); ${ }^{1} \mathrm{H}$ NMR $\left(\mathrm{CDCl}_{3}, 300 \mathrm{MHz}\right) \delta 6.07$ (br, $1 \mathrm{H}), 3.66(\mathrm{t}, J=6.8 \mathrm{~Hz}, 2 \mathrm{H}), 3.40(\mathrm{t}, J=6.6 \mathrm{~Hz}), 2.22(\mathrm{~m}, 2 \mathrm{H}), 1.46(\mathrm{~s}$,
$6 \mathrm{H}) ;{ }^{13} \mathrm{C} \mathrm{NMR}\left(\mathrm{CDCl}_{3}, 75 \mathrm{MHz}\right) \delta 177.2,156.2,58.8,49.1,36.2,27.5$, 25.1; HRMS (MALDI-TOF) calculated for $\mathrm{C}_{8} \mathrm{H}_{13} \mathrm{~N}_{5} \mathrm{O}_{2} \mathrm{Na}[\mathrm{M}+\mathrm{Na}]^{+}$: 234.0961, found: 234.0934 .

\section{6. "Cick" linkage between PMBAA-PET and azido moieties}

The dyansyl-azide $\mathbf{1}(\underline{0.33 \mathrm{mmol}})$ and $50 \mu \mathrm{L}$ Triton X-100 were dissolved in $20 \mathrm{~mL}$ mixed solvent $t-\mathrm{BuOH} / \mathrm{H}_{2} \mathrm{O}(1: 1)$. PMBAA-PET $(0.64 \mathrm{~g}, \quad \mathrm{IP}=7.6 \%$, total $\mathrm{MBAA}=0.64 \times 0.076 /$ $(1+0.076)=45.21 \mathrm{mg}, 0.33 \mathrm{mmol})$ was immersed in this mixed solvent for $30 \mathrm{~min}$ before $\mathrm{Na}$ ascorbate $(34 \mathrm{mg}, 0.17 \mathrm{mmol}$ ) and aqueous $\mathrm{CuSO}_{4}(33 \mu \mathrm{L}, 1 \mathrm{M}$ ) were added to initiate the "click" reaction. The reaction mixture was continuously shaken for different periods of time at room temperature. Subsequently, the treated fabric was rinsed with $t-\mathrm{BuOH}$ and deionized (DI) $\mathrm{H}_{2} \mathrm{O}$ respectively, then immersed in mixed solvent $t-\mathrm{BuOH} / \mathrm{H}_{2} \mathrm{O}$, and the shaking durations used during the "click" reaction were repeated. The resultant PET fabric, named PMBAA-PET-1, was finally rinsed again 3 times with $\mathrm{DI}_{2} \mathrm{O}$ and dried under vacuum for $24 \mathrm{~h}$. Control samples were produced following the same protocol except that no $\mathrm{Cu}^{2+}$ catalyst was added.

The process was repeated for the "click linkage" between PMBAA-PET and 2/per-azido- $\beta-C D$ respectively, and the resultant fabric was referred to as PMBAA-PET-2 and PMBAA-PET-CD. Due to the poor solubility of per-azido- $\beta-C D$, we specifically used DMSO/ $\mathrm{H}_{2} \mathrm{O}(3: 1)$ as a mixed solvent instead of $t-\mathrm{BuOH} / \mathrm{H}_{2} \mathrm{O}(1: 1)$ for the "click" reaction.

\subsection{Quantification of 2 clicked onto PMBAA-PET}

The quantities of clicked $\mathbf{2}$ were estimated from the ratio of two peak heights $1700 \mathrm{~cm}^{-1}$ and $725 \mathrm{~cm}^{-1}(\mathrm{H} 1700 / \mathrm{H} 725)$ in FTIR spectra. These heights are characteristic of the carbonyl stretching of hydantoin and the aromatic $\mathrm{C}-\mathrm{H}$ bending in PET, respectively. A calibration curve was constructed from the FTIR spectra of PMBAAPET coated with a known amount of $\mathbf{2}$ (see Figure S1 in the supporting information).

\subsection{Antibacterial assessment of PMBAA-PET-2}

Before evaluating the biocidal activity, the corresponding modified PET samples including PMBAA-PET-2, PMBAA-PET and pristine PET were exposed to a diluted sodium hypochlorite solution. The antibacterial properties of these chlorinated samples were examined according to a modified American Association of Textile Chemist and Colorists (AATCC) test method 100 against a clinical isolate of MDR-E. coli (\#70094), and a clinical isolate of HA-MRSA 
(\#70527). The modified fabrics (PMBAA-PET/PMBAA-PET-2) were cut into two small pieces (round swatch, diameter $=2.4 \mathrm{~cm}$ ). One of the pieces was put in a sterilized container and $60 \mu \mathrm{L}$ of an aqueous suspension containing $10^{7}$ colony forming units (CFU)/mL of HAMRSA or MDR-E. coli was placed onto the surface of the fabric. The fabric was then "sandwiched" using another piece of identical fabric. A sterilized $50 \mathrm{~mL}$ beaker was placed on top of these two fabrics to ensure intimate contact. After contact for a predetermined time, the entire "sandwich" was placed into $10 \mathrm{~mL}$ of $1.0 \%$ sodium thiosulfate aqueous solution to quench the residual active chlorine on the fabrics. The resultant mixture was then vigorously shaken for $2 \mathrm{~min}$ before an aliquot $(100 \mu \mathrm{L})$ of the solution was removed and then serially diluted. $100 \mu \mathrm{L}$ of each dilution was placed onto a nutrient agar plate. The same procedure was applied to the chlorinated pristine PET as control. Viable bacterial colonies on the agar plates were counted after incubation at $37{ }^{\circ} \mathrm{C}$ for $24 \mathrm{~h}$. Bacterial reduction is reported according to the following equation:

Percentage reduction of bacteria $(\%)=(\mathrm{A}-\mathrm{B}) / \mathrm{A} \times 100$ $\log$ reduction $=\log (\mathrm{A} / \mathrm{B})$

where $A$ is the number of bacteria retrieved from chlorinated pristine PET $(\mathrm{CFU} / \mathrm{mL})$, and $B$ is the number of bacteria retrieved from PMBAA-PET or PMBAA-PET-2 (CFU/mL).

\subsection{Quantification of $\beta-C D$ on PMBAA-PET-CD surface}

The inclusion complex between PMBAA-PET-CD (ca. $80 \mathrm{mg}$ ) and gaseous cyclohexylamine was carried out at room temperature for $24 \mathrm{~h}$ in a desiccator having an excess $(20 \mathrm{~mL})$ of cyclohexylamine at the bottom. The fabric sample was then dried for $2 \mathrm{~h}$ at $120^{\circ} \mathrm{C}$ to remove the majority of the loosely adsorbed cyclohexylamine. The total amount of complexed and adsorbed amine was soxhletextracted for $4 \mathrm{~h}$ into $150 \mathrm{~mL}$ DI water and determined by acidbase volumetric titration using standard $0.08 \mathrm{M} \mathrm{HCl}$ solution and methyl-red indicator. PMBAA-PET was used as control sample.

\subsection{Complexation ability test of PMBAA-PET-CD}

At room temperature, PMBAA-PET-CD fabric (110 mg) was immersed in $10 \mathrm{~mL}$ ethanol solution of Coumarin 6 (final concentration $2 \mathrm{mM}$ ) and continuously shaken for $12 \mathrm{~h}$. Then the samples were taken out of the solution, rinsed with ethanol for several times and washed for additional $2 \mathrm{~h}$ in ethanol. Complexation ability was investigated by checking fluorescence of the surface of the sample under UV light (254 nm). PMBAA-PET was used as control sample.

\subsection{Preparation of azido-fluorescent BSA}

BSA (200 mg) was dissolved in $\mathrm{NaHCO}_{3}$ buffer $(4 \mathrm{~mL} 0.2 \mathrm{M})$ and FITC (20 mg, $0.051 \mathrm{mmol}$, in $0.8 \mathrm{~mL}$ DMF, 17 equiv.) was added to this protein solution and continuously stirred overnight before dialysis $(\mathrm{MD}=7000$ ). The dialysis ended up when no fluorescence was seen in the diffusion solution, whereupon azidohexanoic acid-NHS solution ( $14.4 \mathrm{mg}, 0.06 \mathrm{mmol}, 20$ equiv., in $0.03 \mathrm{~mL}$ DMF) was added to the FITC labeled BSA solution and stir continued for $15 \mathrm{~h}$. The final azido-fluorescent BSA, named FITC$B S A-N_{3}$, was obtained after further dialysis for $24 \mathrm{~h}$ and stored at $4{ }^{\circ} \mathrm{C}$ before further use. BSA- $\mathrm{N}_{3}$ was also prepared in a similar

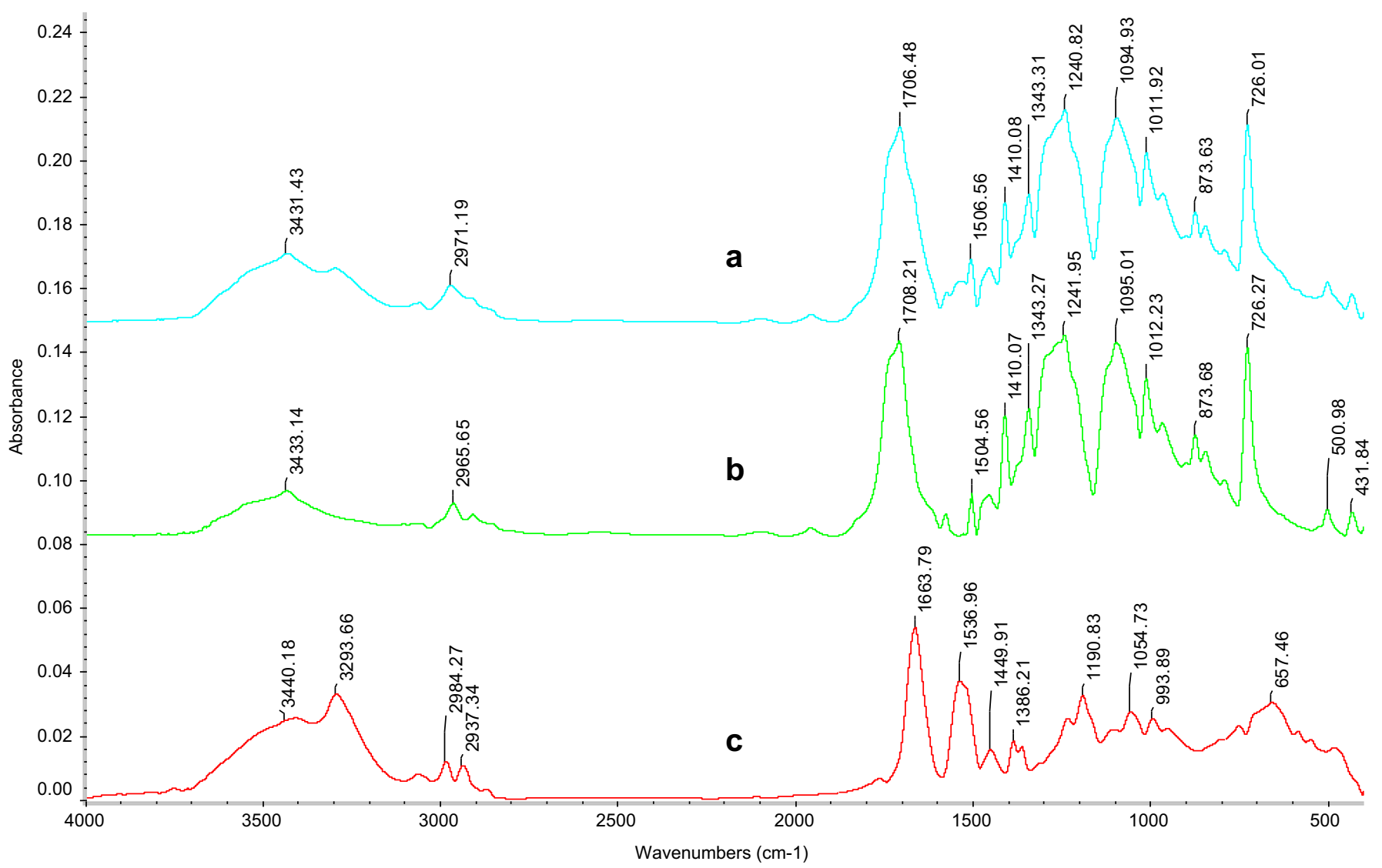

Fig. 1. FTIR spectra of a) PMBAA-PET (IP = 7.6); b) pristine PET; c) subtracted FTIR spectrum of PMBAA-PET and pristine PET. 
manner by chemical modification of BSA with azidohexanoic acid-NHS.

\subsection{2. "Cick" linkage between PMBAA-PET and FITC-BSA-N $\mathrm{N}_{3}$}

At room temperature, PMBAA-PET fabric $(20 \mathrm{mg})$ was immersed in FITC-BSA-N $\mathrm{N}_{3}$ solution $(2 \mathrm{mg} / \mathrm{mL}$, total $3 \mathrm{~mL}$ ). A catalysis solution (total $0.3 \mathrm{~mL}$, containing $0.15 \mu \mathrm{mol} \mathrm{CuSO}{ }_{4}$ and $0.6 \mu \mathrm{mol} \mathrm{Na}$ ascorbate) was added to initiate the click reaction. After continuous shaking for $24 \mathrm{~h}$, the fabric samples was taken out and rinsed five times with DI water, then ultrasonicated for 20 min by treating with $5 \mathrm{M} \mathrm{NaCl}$ and $1 \% \mathrm{SDS}$ respectively. Finally, the fabric sample was air dried overnight and submitted to fluorescent observation. A click control sample was obtained by simply immersing PMBAA-PET in azido-BSA-FITC solution on the same scale without catalyst solution. The obtained fabric, conferred with fluorescent BSA protein, was referred to as PMBAA-PET-BSA-FITC.

The "click" reaction between PMBAA-PET and $\mathrm{N}_{3}$-BSA was also completed yielding PMBAA-PET-BSA.

\subsection{Quantification of covalently attached BSA}

PMBAA-PET-BSA was treated with $2 \mathrm{~mL} 6 \mathrm{~N} \mathrm{HCl}$ and autoclaved at $120{ }^{\circ} \mathrm{C}$ for $15 \mathrm{~min}$. The cooled resulting system was then neutralized with $1.5 \mathrm{~mL} 5 \mathrm{~N} \mathrm{NaOH}$ and $7.5 \mathrm{~mL} 1 \mathrm{M} \mathrm{NaOAc}$ buffer $(\mathrm{pH}$ 4.7). One milliliter ninhydrin reagent was added to an aliquot $\left(2 \mathrm{~mL}\right.$ ) of the solution followed by heating at $100{ }^{\circ} \mathrm{C}$ for $5 \mathrm{~min}$ to produce a purple color. Finally, $5 \mathrm{~mL} 95 \%$ ethanol was added to this purple solution, and UV absorbance was checked at $570 \mathrm{~nm}$. A standard calibration curve was constructed by using a known amount of BSA. The same procedure was repeated for PMBAA-PET and the "click" control sample. The test was performed in triplicate.

\section{Results \& discussion}

"Click Chemistry" is quite attractive to furnish surfaces with different functionalities because of its good selectivity, high reactivity and mild reaction conditions. To this end, either azido or alkynyl group needs to be incorporated onto the surface of PET

a survey: 1 (NZ_PET_4_6_10)

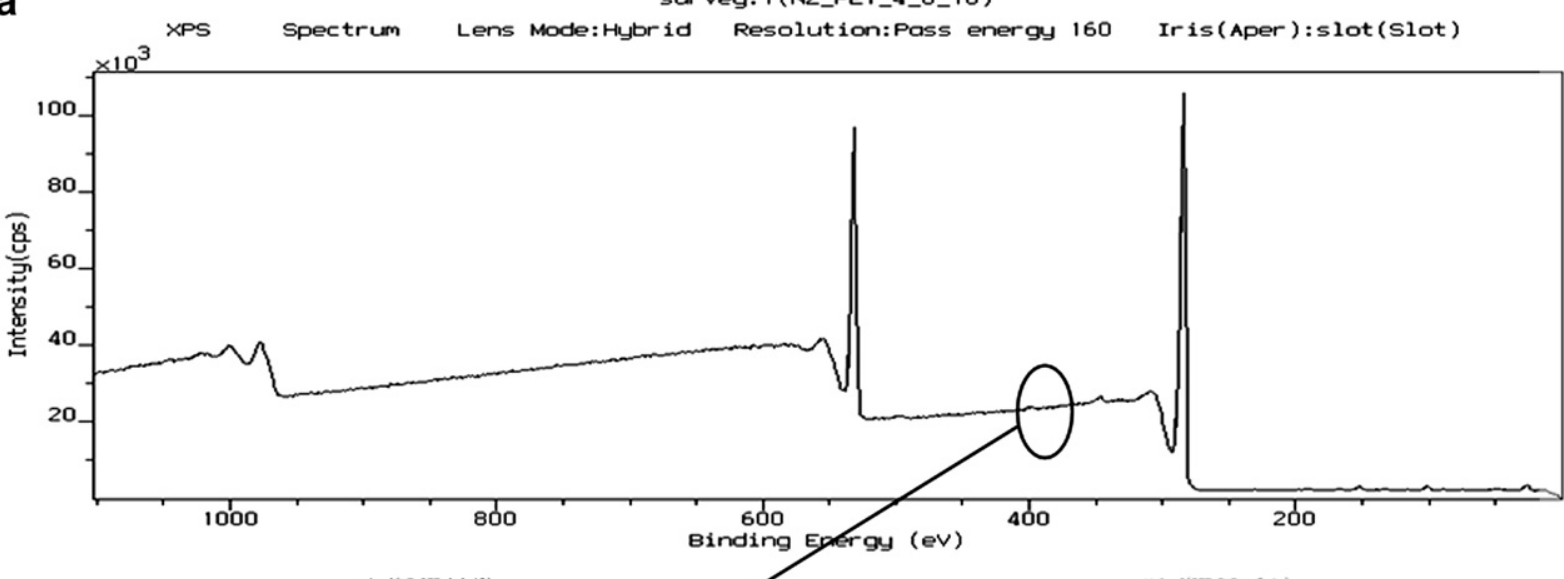

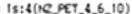

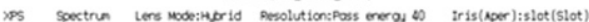
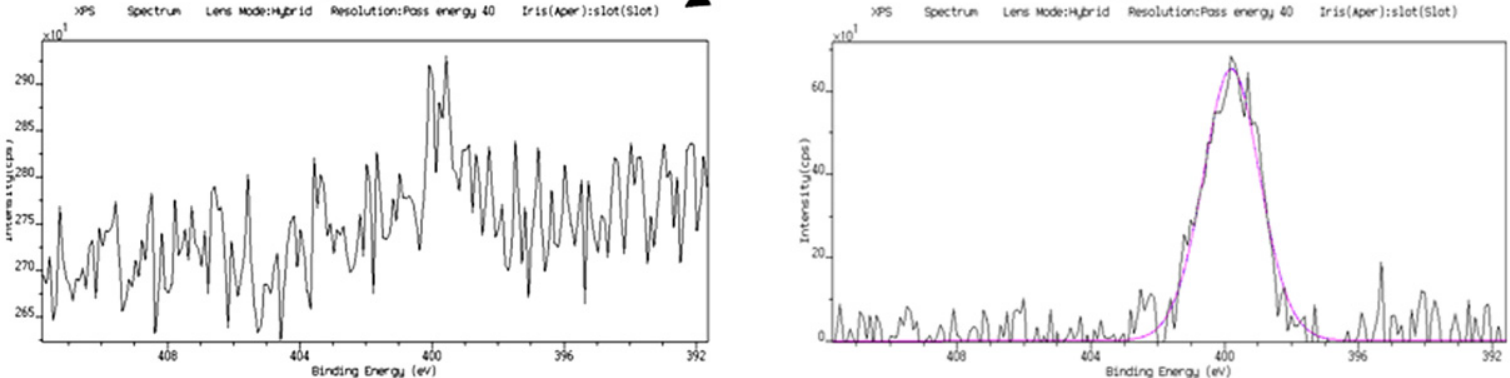

b Survey: 1 (PET_PMBAA_Omin)

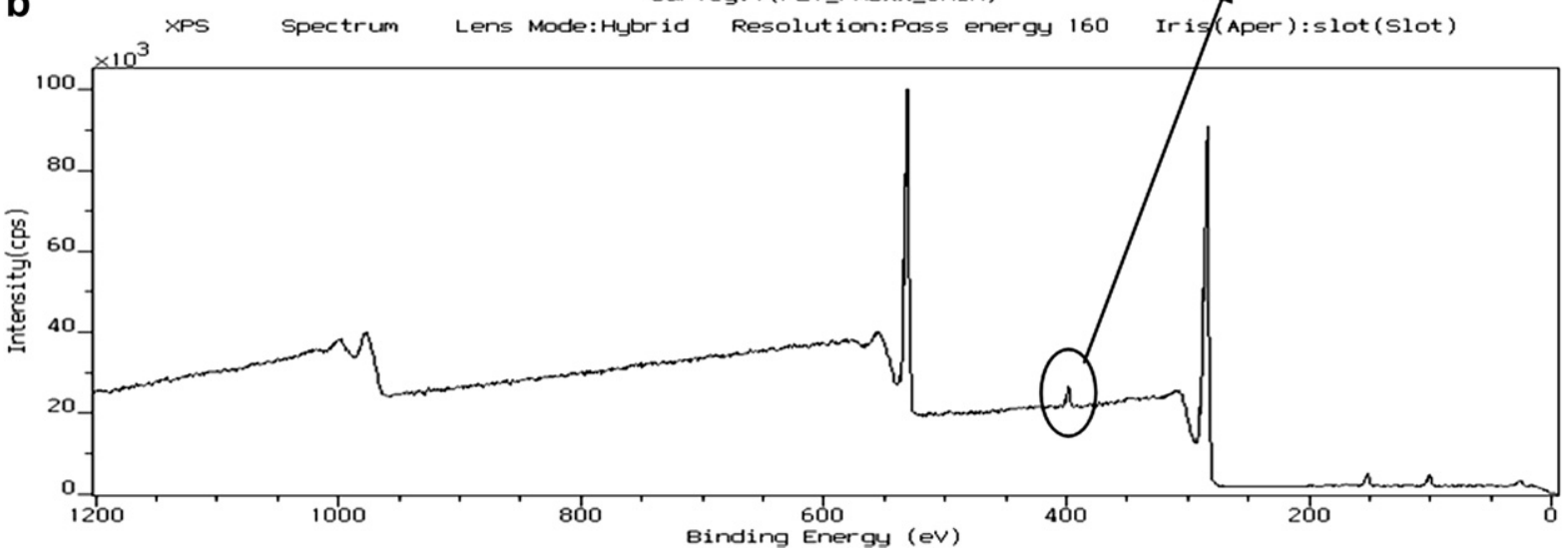

Fig. 2. XPS Survey of a) pristine PET and b) PMBAA-PET (IP $=7.6 \%$ ). 
substrates. Since we have previously immobilized polyacrylamide (PAM) onto the PET surface by means of surface IPN method [11,12], we initially tried to design and prepare two acrylamide (AM) derivatives that carry "clickable" handles: MBAA and N-(1-azido-2methylpropan-2-yl)acrylamide (AMPAA). Retrosynthesis strategy (see Scheme S1 in the supporting information) indicated that these two monomers could be produced by reacting acryloyl chloride with a corresponding amine. However, compared with AMPAA, the synthesis of MBAA seemed more convenient because the 2methylbut-3-yn-2-amine (4) is commercially available. Another starting material, 1-azido-2-methylpropan-2-amine (5), can be obtained only from 2-amino-2-methylpropan-1-ol (6) after a twostep chemical reaction including azide group substitution and bromination with environmentally unfriendly concentrated $\mathrm{HBr}$. The synthesis of MBAA has been reported previously [22], its polymerization, however, has not been investigated.

\subsection{MBAA immobilization on PET fabric}

The clickable monomer MBAA, obtained as a white solid after purification, was co-polymerized with MBA (crosslinker) in the methanol-swollen surface of PET upon UV (365 nm) irradiation to form a thermoplastic semi-IPN (Scheme 2), resulting in the alkynyl handle terminated polyester: PMBAA-PET.

PMBAA-PET was characterized by FTIR and XPS to confirm the immobilization of PMBAA. Fig. 1 presents the FTIR spectra of pristine PET (a), PMBAA-PET (b), and the result of subtracting FTIR spectrum of pristine PET from that of PMBAA-PET (c). In the subtracted FTIR spectrum, there were two new peaks at 3293 and $1663 \mathrm{~cm}^{-1}$, which could be assigned to the stretching of alkynyl $\mathrm{C}-\mathrm{H}$ and the characteristic amide I band of $\mathrm{C}(\mathrm{O})-\mathrm{NH}$ in PMBAA respectively. The subtracted FTIR spectrum implied the successful immobilization of PMBAA on PET.

As can be seen in Fig. 2, a distinct nitrogen peak appeared in the XPS survey of PMBAA-PET, while no detectable nitrogen was observed in that of pristine PET, confirming that PMBAA was successfully immobilized.

\subsection{Synthesis of $\mathbf{1}$ and $\mathbf{2}$}

Synthesis of $\mathbf{1}$ and $\mathbf{2}$ is outlined in Scheme 3. First, dansyl-azide $\mathbf{1}$ was prepared by reacting dansyl chloride with 1-azidohexanol at room temperature. After purification on flash chromatography, 1 was obtained as fluorescent viscous oil. In a similar protocol as the literature [26], synthesis of bromide 3 was completed by alkylation of 5,5-dimethyhydantoin with excess dibromopropane in presence of anhydrous $\mathrm{K}_{2} \mathrm{CO}_{3}$. Azide group substitution in heated DMF afforded an azido-hydantoin analog 2 as a viscous colorless oil. NMR and HRMS confirmed the structure of these synthetic compounds.

\subsection{Effect of irradiation duration on PMBAA immobilization}

The initiator used in this study is benzophenone, which is a Norrish type II photoinitiator with a high potency in abstracting hydrogen from the substrate. Theoretically, two mechanisms could contribute to the immobilization of PMBAA on PET: a) the polymer chains of PMBAA are chemically grafted on PET backbone; and b) the chemically crosslinked polymer chains of PMBAA are interlocked with physically crosslinked polymer chains of substrate PET. Since methanol was used as the solvent, the initiator BP can easily abstract hydrogen from methanol instead of from PET substrate. So, the major mechanism of immobilization may still be the formation of the described interpenetrating network: thermoplastic semiIPN. Our previous publication [11] concluded that IPN is the major mechanism for the immobilization based on the fact that immobilization of PAM is also successful using an initiator without the ability of hydrogen abstraction. Fig. 3 presents a plot of the immobilization percentage as a function of the irradiation time. A sigmoid shape curve, similar to the case of using acrylamide as monomer [11], was obtained. The observed lag time or induction period ( $15 \mathrm{~min}$ ) may be due to the inhibition effect of the oxygen in the air. It shows that MBAA can effectively copolymerize with MBA to form a thermoplastic semi-IPN with PET for durable immobilization.

\section{4. “Click” linkage between PMBAA-PET and dyansyl-azide (1)}

To validate the possibility of introducing specific azidofunctionalities onto PMBAA-PET substrate, dansyl-azide $\mathbf{1}$ was adopted as a model compound to carry out the "click" reaction. A stoichiometric amount of $\mathbf{1}$ based on the total alkyne content on PMBAA-PET was discharged into the reaction system and $\mathrm{Na}$ ascorbate $/ \mathrm{Cu}^{2+}$ was used as catalyst.

Uniform and green fluorescence was observed on "click" PMBAA-PET samples (Fig. 4), whereas only blue auto-fluorescence of PET showed on the control PMBAA-PET samples. The intensity of the fluorescence on PMBAA-PET increased with extended reaction time. These results indicate that the "click" reaction was successful and that PMBAA was uniformly distributed on the surface of PMBAA-PET.

To demonstrate the possibility of creating region-selective modification of PET, a piece of PET fabric swollen with the methanol swelling solution was covered with a same-sized piece of aluminum foil engraved with letters "V" and "I" during exposure to UV irradiation. The so-formed PMBAA-PET was then clicked with dansyl-azide 1 to visualize the distribution of PMBAA. As depicted in Fig. 5, two letters "V" and "I" were clearly "printed" on the PET fabric, demonstrating the formation of PMBAA IPN within confined regions. The "printed" letters appeared coarser than the template. This is understandable since the radical generated under UV irradiation can diffuse to adjacent regions. By comparing the width of the fluorescence lane (letter "I") to that of corresponding foil template, the diffusion ratio was estimated to be 1.37 (see Figure S2 in the supporting information). The region-selective modification allows specific alignment of functionalities and even different biofunctions onto PET.

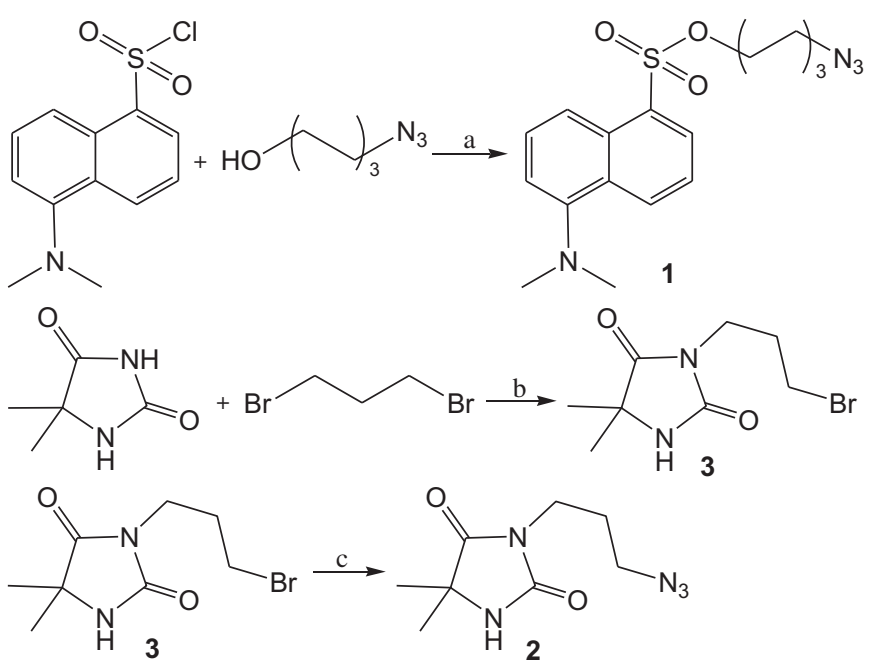

Scheme 3. Synthesis on dansyl-azide $\mathbf{1}$ and azido-hydantoin analog $\mathbf{2}$. Reagent and conditions: a) pyridine, $\mathrm{CH}_{2} \mathrm{Cl}_{2}, \mathrm{rt}, 24 \mathrm{~h}, 83 \%$; b) b) $\mathrm{K}_{2} \mathrm{CO}_{3}$, acetone, reflux, $4 \mathrm{~h}, 82 \%$; c) excess $\mathrm{NaN}_{3}$, DMF, $80{ }^{\circ} \mathrm{C}$, overnight, $90 \%$. 


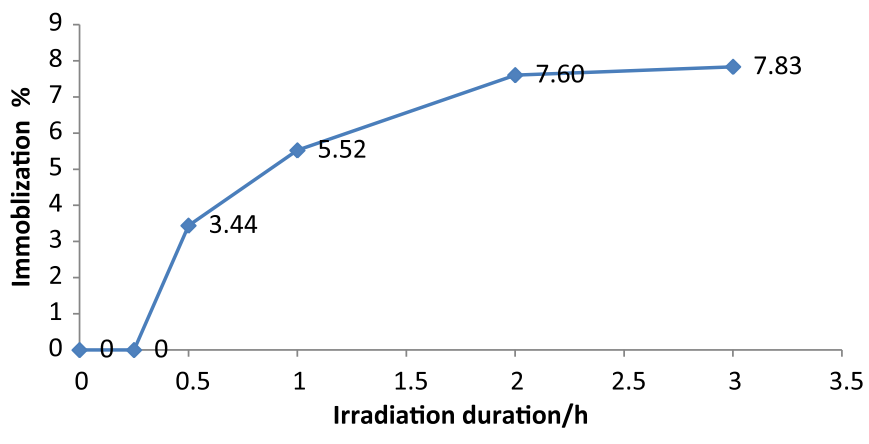

Fig. 3. Effect of irradiation duration on the immobilization percentage (IP) of PMBAAPET. Recipe: MBAA $2 \mathrm{~mol} \mathrm{~L}^{-1}$, MBA $0.045 \mathrm{~mol} \mathrm{~L}^{-1}$, and BP $0.082 \mathrm{~mol} \mathrm{~L}^{-1}$.

In homogeneous solution, the $\mathrm{Cu}(\mathrm{I})$-catalyzed azide-alkyne cycloaddition generally goes to completion within seconds [27]. However, it may take hours in case of the heterogeneous "click" reaction such as the linkage between PMBAA-PET and 1. The kinetics of the click reaction can be monitored by elemental analysis and XPS characterization. The weight percents of dansyl-azide 1 covalently linked onto PMBAA-PET, as derived from sulfur contents, are plotted against reaction duration in Fig. 6. The amount of 1 increased with the reaction time, and leveled off at the reaction time of 2 h. Therefore, we next carried out all subsequent "click" reactions for $2 \mathrm{~h}$. In forming the thermoplastic semi-IPN in the surface of PET substrate, PMBAA was welded on the surface and a significant amount of PMBAA chains were buried in the IPN interface. Only some PMBAA chains that poked out were accessible for further click reaction. The equilibrium amount of $\mathbf{1}$ (2.7\% of the substrate or $0.00727 \mathrm{~mol}$ per gram of the PMBAA-PET substrate) implied that $15.9 \%$ of immobilized alkynyl handles were accessible for the click reaction. In XPS spectrum of PMBAA-PET-1 (Fig. 7), even though the $\mathrm{N}$ 1s peak seemed to be just a single peak, it was still deconvoluted and fitted to three peaks assigned to $\mathrm{CONH} /$ $\mathrm{RN}\left(3^{\circ}\right)(399.8 \mathrm{eV}$, peak III), $\mathrm{N}-\mathbf{N}=\mathbf{N}(400.8 \mathrm{eV}$, peak I), and $\mathbf{N}-\mathrm{N}=\mathrm{N}$ (401.7 eV, peak II) [28] considering sufficient evidence from elemental analysis and fluorescent images. The ratio of the peak areas (III: I: II) was about 5.6:2:1. The existence of sulfur peaks also lent support to the successful bonding of dansyl dye $\mathbf{1}$ since sulfur exists only in $\mathbf{1}$.

Furthermore, the successful linkage of fluorescence agent $\mathbf{1}$ to PMBAA-PET also demonstrated that PMBAA-PET might be a good platform to furnish the surface with various bio-functionalities via "click" chemistry method.

\subsection{Clicking of bio-functions}

Using the above optimized conditions, the azides including 2, per-azido- $\beta-\mathrm{CD}$ and $\mathrm{BSA}-\mathrm{N}_{3}$ were attached onto PMBAA-PET surface to provide the PET substrates presenting 2, $\beta-C D$, and BSA protein (Scheme 2). The conversion percentage of the immobilized alkynyl group to the "click" linkage was estimated from FTIR, CD cavity titration and BSA protein quantification analysis and listed in Table 1. Conversion ratio for grafting 2 is $11.0 \%$, which is lower than that of grafting $\mathbf{1}$. The aromatic structure in $\mathbf{1}$ may offer a better affinity towards PET, leading to higher heterogeneous reaction efficiency. Considering that not all immobilized alkynyl groups are available for a subsequent "click" linkage, the yields of these "click" reactions (Table 1 ) were calculated based on the total amount of accessible alkyne derived from the reaction between PMBAA-PET and 1 (15.9\% of all the immobilized alkyne). The lower efficiency for grafting the per-azido- $\beta-\mathrm{CD}$ and azido-BSA is probably due to the steric hindrance of the pretty big carbohydrate structure and the huge protein molecule.

\subsection{PET presenting azido-hydantoin analog (2)}

$\mathrm{N}$-Chloro-hydantoin was found to be a promising candidate for antibacterial function due to its superior biocidal efficacy, stability and regenerability. Its derivatives have been coated, radically grafted onto PET or covalently bonded to aminolyzed PET $[14,29,30]$. Conferring azido-hydantoin analog 2 onto PMBAA-PET by means of "click" linkage offers another alternative to the above methods. However, since there is an amide group in the clickable polymer PMBAA, N-chloramine can also be generated from this amide as well. So, in the structural design MBAA, precaution has been practiced to avoid $\alpha$ hydrogen to the amide $\mathrm{NH}$ - so that no dehydrochlorination will occur [31] after the $\mathrm{N}-\mathrm{H}$ is converted to $\mathrm{N}-\mathrm{Cl}$ during chlorination (see Scheme $\mathrm{S} 1$ in the supporting information). The absence of $\alpha$ hydrogen enhances the chemical stability of PMBAA against hydrolysis during chlorination [31].

We next covalently bound 2 onto PMBAA-PET surface. FTIR spectrum of PMBAA-PET-2 is presented in Fig. 8. After subtracting PMBAA-PET spectrum from that of PMBAA-PET-2, two new peaks 1750 and $1694 \mathrm{~cm}^{-1}$ appeared, which can be assigned to stretching

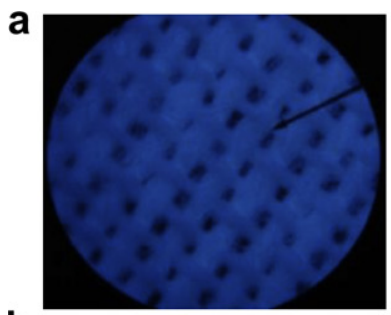

b

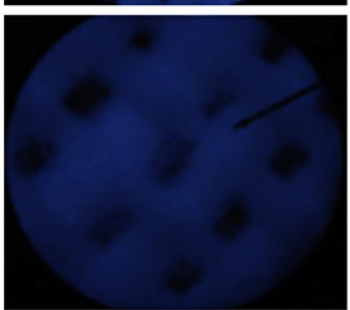

PMBAA-PET
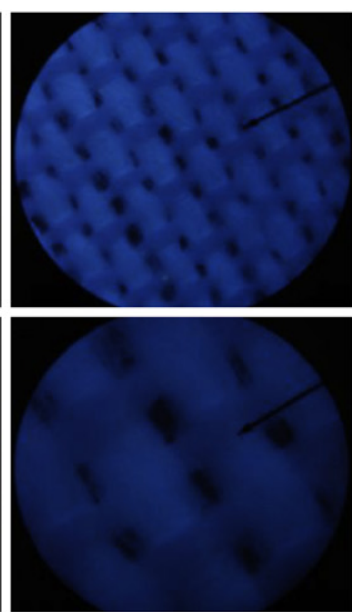

control (120 min)
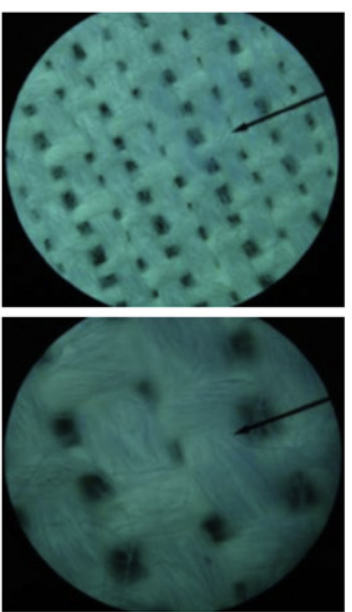

“click" $15 \mathrm{~min}$
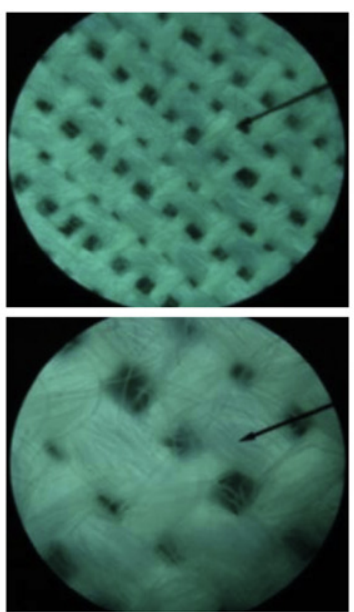

"click" $30 \mathrm{~min}$
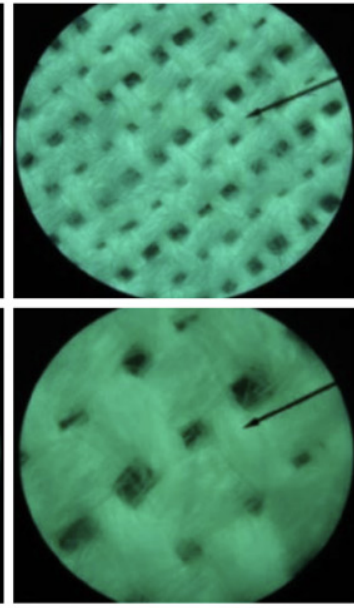

"click" $120 \mathrm{~min}$

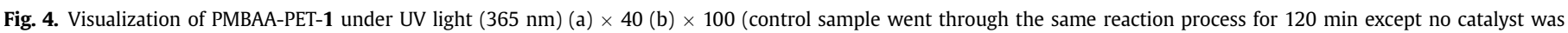
added). 

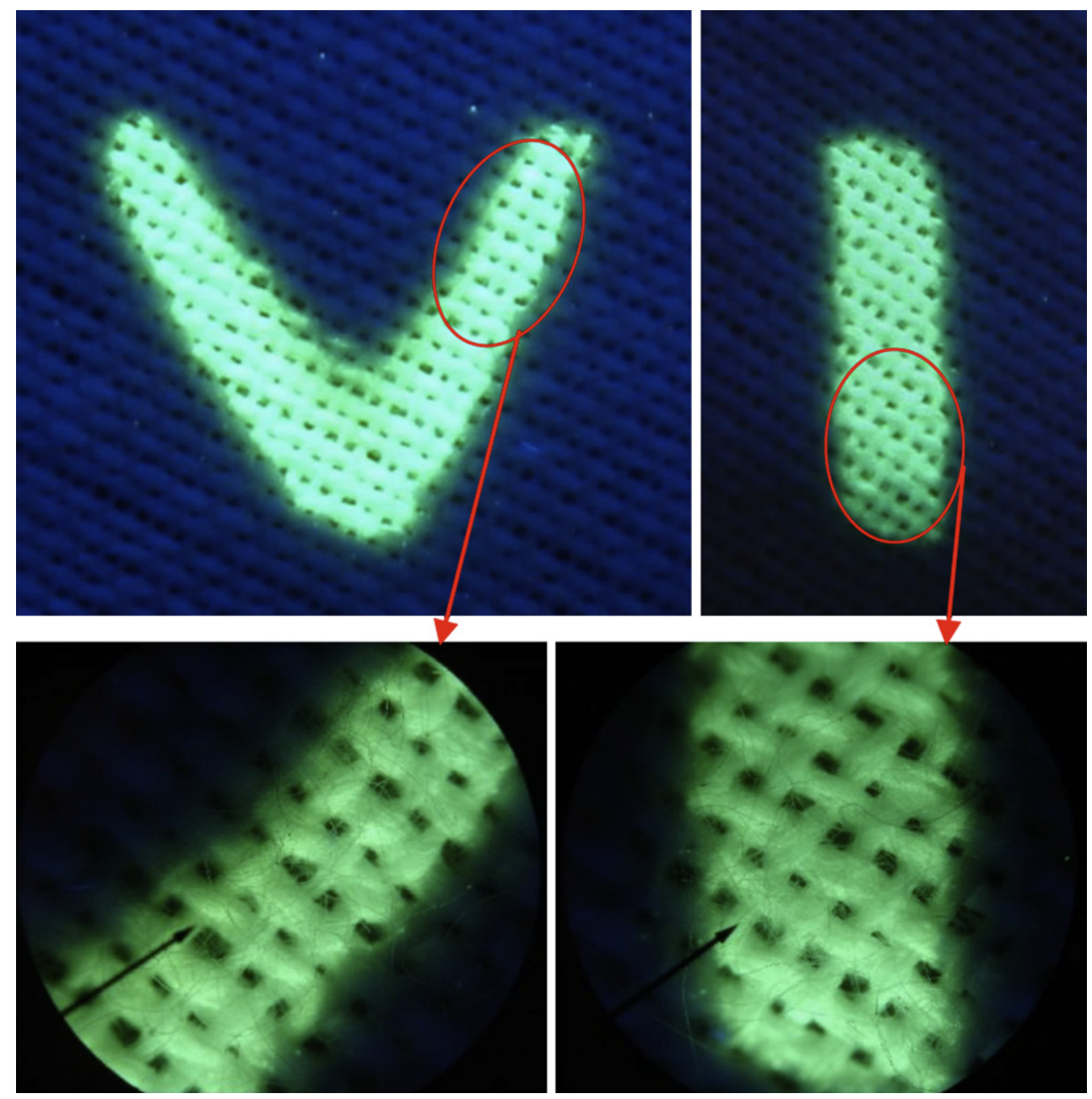

Fig. 5. Visualization of patterned PMBAA-PET-1 under UV light (365 nm).

of two carbonyl groups in hydantoin. Both peaks might be used for the semi-quantification of the amount of successfully clicked azido hydantoin. However, it was found that the peak height ratio of $1700 \mathrm{~cm}^{-1}$ and $725 \mathrm{~cm}^{-1}$ (aromatic $\mathrm{C}-\mathrm{H}$ bending serving as an internal standard) showed a better linearity with the amount of 2 coated on PMBAA PET (when 2 was coated on PMBAA-PET, the carbonyl peak shifted a little from 1694 to $1700 \mathrm{~cm}^{-1}$ ).

The amide bond $(\mathrm{NH})$ of the hydantoin moiety can be chlorinated to produce $\mathrm{N}-\mathrm{Cl}$ thus imparting antibacterial activity to PET

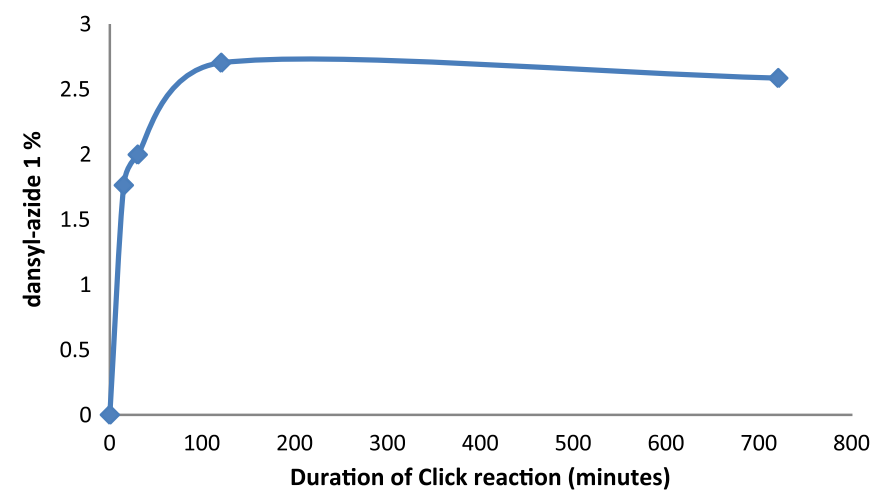

Fig. 6. Progress of the "click" reaction on PMBAA-PET with dansyl-azide 1, monitored by sulfur element analysis after various reaction durations. fabric. PMBAA-PET-2 was chlorinated in 1500 ppm of available chlorine and challenged with HA-MRSA and MDR-E. coli respectively. As shown in Table 2, active chlorine as high as 419 ppm was achieved on PMBAA-PET-2, which is almost double the amount of active chlorine achievable on PET modified using either radical grafting or chemical reaction [14,30]. Within $20 \mathrm{~min}$ of contact, PMBAA-PET-2 demonstrated a total kill of both MRSA and MDRE. coli. Even after only 10 min of contact, PMBAA-PET-2 could still bring more than $92 \%$ of reduction of both bacteria. Consistent with the previous report [30], MDR-E. coli is more resistant to the biocide compared to MRSA according to the reduction data of 5 and $10 \mathrm{~min}$ contact. Even without bonding 2, PMBAA-PET bore $125 \mathrm{ppm}$ active chlorine after chlorination since the acyclic amide of PMBAA can also be converted to $\mathrm{N}$-halamine. But its conversion ratio of $\mathrm{N}-\mathrm{H}$ to $\mathrm{N}-\mathrm{Cl}$ is quite low (around $0.6 \%$ ) probably because of the steric hindrance from the two methyl groups of PMBAA. Compared to PMBAA-PET-2, chlorinated PMBAA-PET showed little antibacterial efficacy (only around $12 \%$ reduction of both bacteria at 20 min of contact). The much better biocidal efficacy of PMBAA-PET-2 is due to not only higher active chlorine content but also better hydrophilicity as denoted by the smaller contact angle $\left(88.4^{\circ}\right.$ as compared to $103.2^{\circ}$ ).

Textiles are susceptible to contamination by various microorganisms. Contaminated medical use textiles such as uniforms and beddings can be important sources of cross-infections, which have already caused serious outbreaks of nosocomial infections in 

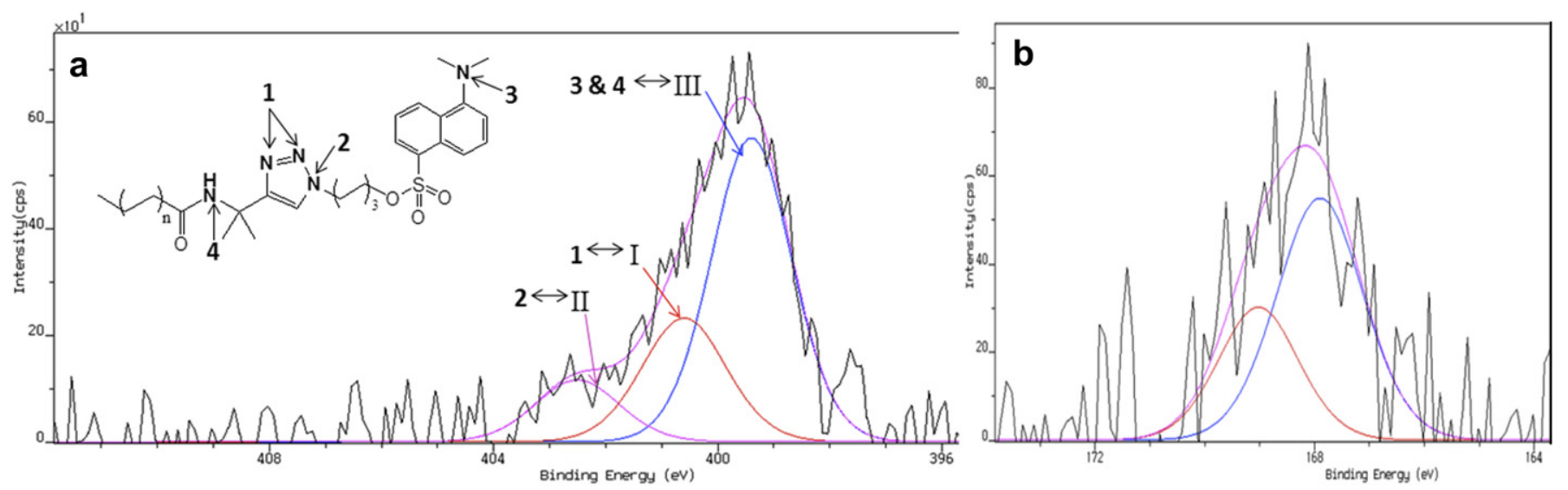

Fig. 7. High resolution N1s (a) and S2p (b) XPS spectra of PMBAA-PET-1 ("click" duration: 120 min).

healthcare facilities. Of the 1561 nosocomial outbreaks studied, $21 \%$ have been attributed to contaminated surfaces, including textiles [32]. PMBAA-PET-2 could be used in hospital settings to offer a surface with the function of self-disinfection and hence decrease the chance of cross-infection.

\section{7. $P E T$ presenting per-azido- $\beta C D$}

$\beta$-Cyclodextrin ( $\beta$-CD) is capable of selectively encapsulating specific guest compounds due to its structural hydrophobic cavity. Efforts have been dedicated to chemical modification of $\beta-C D$ and subsequent applications in enzyme mimic studies, drug delivery system, chromatography separation and purification, and novel functional material development [33]. To demonstrate the versatility of the PMBAA-PET platform for bonding different bioactive molecules, we clicked per-azido- $\beta$ CD onto PMBAA-PET surface. The amount of $C D$ cavities on PMBAA-PET-CD was quantified using a model gaseous compound cyclohexylamine [34] of $1.37 \times 10^{-5} \mathrm{~mol} / \mathrm{g}$. The ability of fixed $\beta-C D$ to form an inclusion complex was further tested by using coumarin 6 as a model guest molecule [35]. After incubating for $12 \mathrm{~h}$ and washing for $2 \mathrm{~h}$, PMBAA-PET-CD loaded coumarin 6 was visualized under UV light (254 nm) (Figure S3). Green fluorescence could be seen clearly on the PMBAA-PET-CD sample, whereas only dim auto fluorescence was observed on the control samples including PET and PMBAA-PET, thus demonstrating the successful formation of inclusion complex between coumarin 6 and fixed $\beta$ $\mathrm{CD}$. Therefore, various bioactive guest molecules could be included into PMBAA-PET-CD to afford specifically biofunctionalized PET materials.

Table 1

Yields for the "click" grafting of the azide molecules onto PMBAA-PET to form PET presenting various bioactive agents.

\begin{tabular}{llllll}
\hline PET fabrics & $\begin{array}{l}\text { Duration of } \\
\text { "click" }\end{array}$ & N/S ratio & S\% & $\begin{array}{l}\text { Converted } \\
\text { alkyne }(\%)\end{array}$ & Yield \\
\hline PMBAA-PET-1 & $15 \mathrm{~min}$ & $14.7^{\mathrm{a}}$ & $0.15^{\mathrm{b}}$ & $9.3^{\mathrm{a}} / 10.4^{\mathrm{b}}$ & \\
& $30 \mathrm{~min}$ & $15.7^{\mathrm{a}}$ & $0.17^{\mathrm{b}}$ & $8.6^{\mathrm{a}} / 11.8^{\mathrm{b}}$ & \\
& $120 \mathrm{~min}$ & $12.2^{\mathrm{a}}$ & $0.23^{\mathrm{b}}$ & $12.2^{\mathrm{a}} / 15.9^{\mathrm{b}}$ & \\
PMBAA-PET-2 & $120 \mathrm{~min}$ & - & - & $11.0^{\mathrm{c}}$ & $69.18 \%$ \\
PMBAA-PET-CD & $120 \mathrm{~min}$ & - & - & $2.77^{\mathrm{d}}$ & $17.42 \%$ \\
PMBAA-PET-BSA & $120 \mathrm{~min}$ & - & - & $0.036^{\mathrm{e}}$ & $0.23 \%$ \\
\hline
\end{tabular}

\footnotetext{
a Based on XPS data analysis.

b Based on elemental analysis.

c Based on FTIR spectra analysis.

d Based on cyclohexylamine-titration.

e Based on BSA quantification analysis.
}

\subsection{PET presenting $B S A$}

Three small azido-functional molecules (1, 2 and per-azido- $\beta$ $\mathrm{CD}$ ) have been covalently bonded onto PMBAA-PET surface via "click" chemistry strategy. We next tested the feasibility of bonding biomacromolecules such as proteins. Actually, protein immobilization has been a hot topic for decades [36]. We herein selected BSA as the model protein to validate the "click" reaction between MBAA-PET and biomacromolecules.

BSA protein was labeled with FITC and azido hexyl linker subsequently by chemically modifying the amino groups of lysine residues [37]. The resultant fluorescent BSA attached with fluorophores and azido tags, termed as FITC-BSA- $\mathrm{N}_{3}$, was thus obtained after dialysis. The following "click" process between FITC-BSA-N $\mathrm{N}_{3}$ and PMBAA-PET was carried out at room temperature using $\mathrm{Cu}^{2+}$ / $\mathrm{Na}$ ascorbate as catalyst [38]. After rinsing with $5 \mathrm{M} \mathrm{NaCl}$ and $1 \%$ SDS respectively, the sample was observed under fluorescence microscope.

In Fig. 9, there existed a dim green fluorescence on PMBAA-PET control and pristine PET control even after thorough rinsing, indicating a strong physical adsorption of BSA on the fabric surface. Such a phenomenon is regarded as reasonable because BSA has a high surface affinity and usually adsorbs on both hydrophilic and hydrophobic surfaces $[39,40]$. The much stronger green fluorescence on PMBAA-PET-BSA-FITC indicated that FITC-BSA-N $\mathrm{N}_{3}$ was successfully attached onto PMBAA-PET surface via the expected "click" linkage.

Since BSA protein was attached on PMBAA-PET surface via a durable covalent triazole linkage, it cannot be cleaved off for quantification. Therefore, ninhydrin method [41] for protein quantification was adopted after the bonded protein was hydrolyzed into amino acids through autoclaving treatment $\left(121^{\circ} \mathrm{C}, 6 \mathrm{M}\right.$ $\mathrm{HCl}$ ). Physically adsorbed BSA on PMBAA-PET was estimated to be $0.46 \mu \mathrm{g} / \mathrm{mg}$ while the covalently attached BSA was $1.6 \mu \mathrm{g} / \mathrm{mg}$ (raw data are shown in Figure S4). This is in accordance with the fluorescent intensity as presented in Fig. 9. The density of the covalently bonded BSA in our study is lower than those reported on microspheres and nanofibrous membranes [41,42] partly due to the much lower specific surface area of our PET fabric made of coarse fibers $(>20 \mu \mathrm{m})$.

As shown in Table 1, BSA-“click" reaction conversion $(0.036 \%$ mol) was much lower than other "click" linkage reaction. Compared with small functional molecules such as $\mathbf{1}$ and $\mathbf{2}$, BSA is much bulkier (MW: 66,776 Da). Once BSA is covalently attached, or even physically adsorbed onto the PMBAA-PET surface, the protein might cover other clickable sites in the proximity and make them 


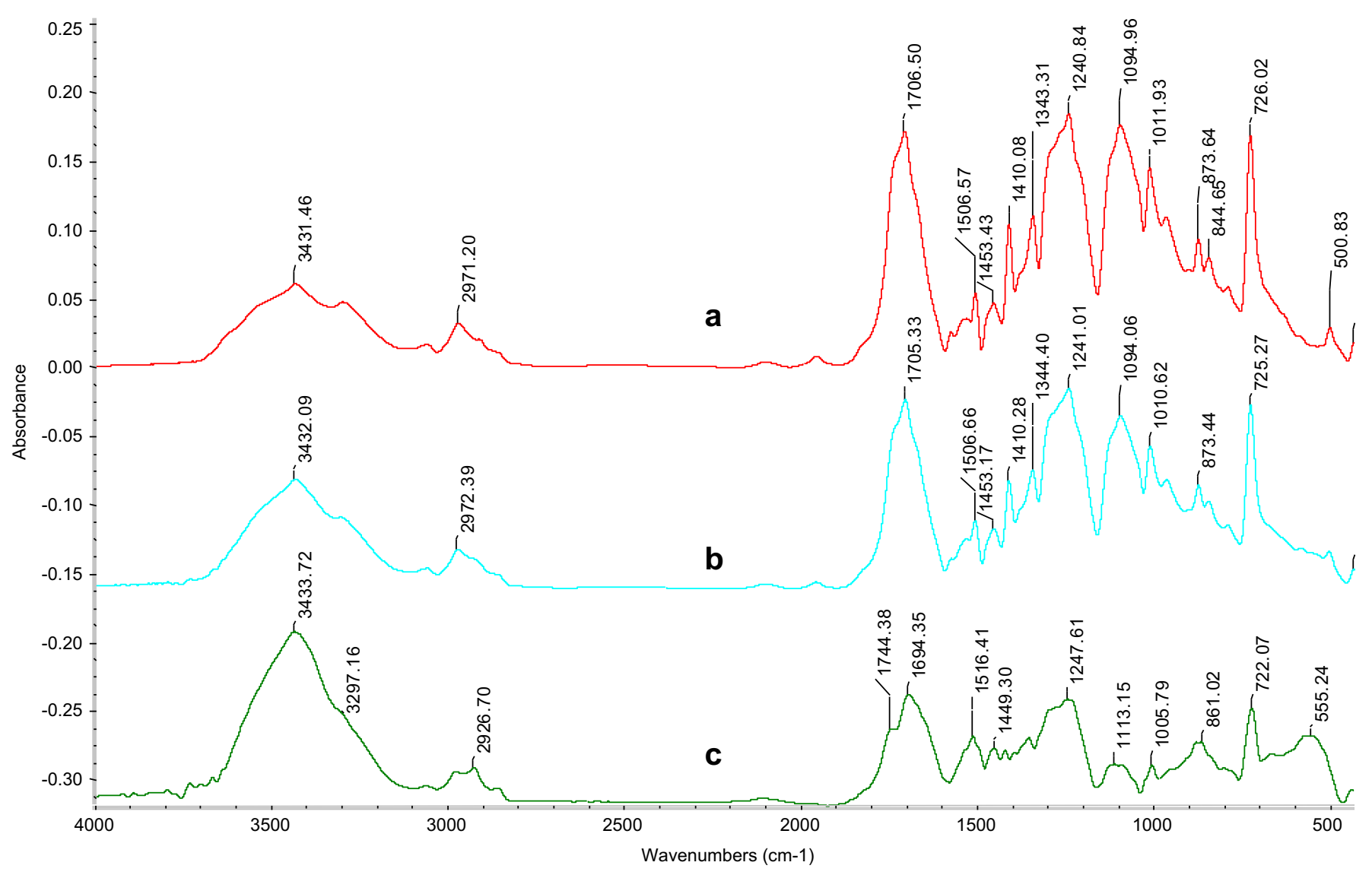

Fig. 8. FTIR spectra of a) PMBAA-PET-2; b) PMBAA-PET (IP = 7.6\%); c) subtracted FTIR spectrum of PMBAA-PET-2 and PMBAA-PET.

inaccessible for further "click" reaction. The "click" linkage efficiency is expected to be improved by introducing a longer, flexible linker between the alkynyl handle and the polymer backbone [43]. Design and synthesis of some new functional monomers with a flexible linker and clickable handles are being undertaken in our group.

Biomimetic strategy, based on biocompatible materials, has been accepted as an efficient way to reconstruct the microenvironment needed for protein immobilization [44,45]. Wang et al. [42] covalently immobilized catalase on BSA-modified PANCAA nanofibrous membrane and found that the tethered catalase exhibited enhanced activity compared with that immobilized directly on membrane surface. Similarly, PMBAA-PET-BSA can be further conferred with other enzyme proteins. Furthermore, to produce BSA-N $\mathrm{N}_{3}, 20$ equiv azidohexanoic acid NHS was used. So there should be residue azide tags in the BSA molecule even after its covalent immobilization. The remaining azide tags together with amino groups of BSA lysine provide reacting sites for further introducing other proteins such as antibodies. This offers a promising route to fabricate biosensors, bioreactors and biomedical devices from PET, the flexible and inert thermoplastic polyester.

It was reported that radially aligned poly( $\varepsilon$-caprolactone) nanofibers induced faster cellular migration and population of dural fibroblast cells than randomly distributed nanofibers [46]. As presented above, regioselective modification of PET with PMBAA could be achieved using the UV-initiated IPN technique, indicating spatially controlled immobilization of proteins on PET can result by clicking azido proteins with the patterned PMBAA-PET for better cell proliferation promotion, or the investigation of cell immobilization and expression.

Table 2

Antibacterial activities of chlorinated PMBAA-PET-2 and PMBAA-PET.

\begin{tabular}{|c|c|c|c|c|c|c|c|c|c|}
\hline \multirow{3}{*}{$\begin{array}{l}\text { Modified PET } \\
\text { samples }\end{array}$} & \multirow{3}{*}{$\begin{array}{l}\text { Active } \\
\text { chlorine } \\
\text { (ppm) }\end{array}$} & \multirow{3}{*}{$\begin{array}{l}\text { Contact angle } \\
\text { (after chlorination) }\end{array}$} & \multirow[t]{3}{*}{ Bacteria } & \multicolumn{6}{|c|}{ Different contact time (min) } \\
\hline & & & & \multicolumn{2}{|l|}{$5 \mathrm{~min}$} & \multicolumn{2}{|l|}{$10 \mathrm{~min}$} & \multicolumn{2}{|l|}{$20 \mathrm{~min}$} \\
\hline & & & & $\begin{array}{l}\text { Percent } \\
\text { reduction }\end{array}$ & $\begin{array}{l}\text { Log } \\
\text { reduction }\end{array}$ & $\begin{array}{l}\text { Percent } \\
\text { reduction }\end{array}$ & $\begin{array}{l}\text { Log } \\
\text { reduction }\end{array}$ & $\begin{array}{l}\text { Percent } \\
\text { reduction }\end{array}$ & $\begin{array}{l}\text { Log } \\
\text { reduction }\end{array}$ \\
\hline PET & 1 & $114.9 \pm 10.4$ & $\begin{array}{l}\text { HA-MRSA } \\
\text { MDR-E. coli }\end{array}$ & 1 & & & & & \\
\hline PMBAA-PET & $125 \pm 10$ & $103.2 \pm 9.8$ & $\begin{array}{l}\text { HA-MRSA } \\
\text { MDR-E. coli }\end{array}$ & $\begin{array}{l}5.3 \% \\
1.0 \%\end{array}$ & $\begin{array}{l}0.02 \\
0.004\end{array}$ & $\begin{array}{l}12.0 \% \\
10.9 \%\end{array}$ & $\begin{array}{l}0.06 \\
0.05\end{array}$ & $\begin{array}{l}12.5 \% \\
11.5 \%\end{array}$ & $\begin{array}{l}0.06 \\
0.05\end{array}$ \\
\hline PMBAA-PET-2 & $419 \pm 19$ & $88.4 \pm 7.9$ & $\begin{array}{l}\text { HA-MRSA } \\
\text { MDR-E. coli }\end{array}$ & $\begin{array}{l}59.1 \% \\
40.6 \%\end{array}$ & $\begin{array}{l}0.39 \\
0.23\end{array}$ & $\begin{array}{l}95 \% \\
92 \%\end{array}$ & $\begin{array}{l}1.31 \\
1.10\end{array}$ & $\begin{array}{l}100 \% \\
100 \%\end{array}$ & $\begin{array}{l}7.20 \\
7.28\end{array}$ \\
\hline
\end{tabular}

\footnotetext{
${ }^{\text {a }}$ Concentration of HA-MRSA was $1.6 \times 10^{7} \mathrm{CFU} / \mathrm{mL}$.

b Concentration of MDR-E. coli was $1.9 \times 10^{7} \mathrm{CFU} / \mathrm{mL}$.
} 
a

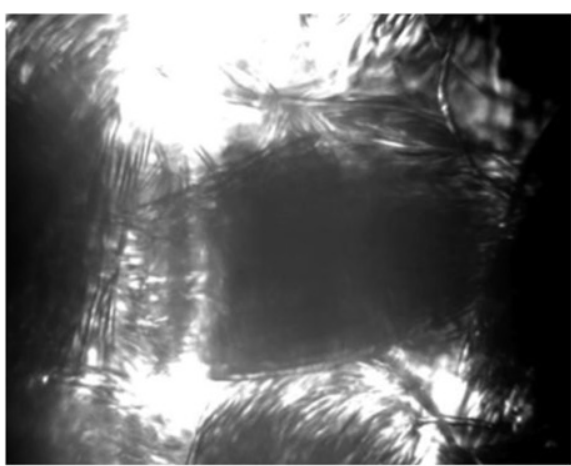

b

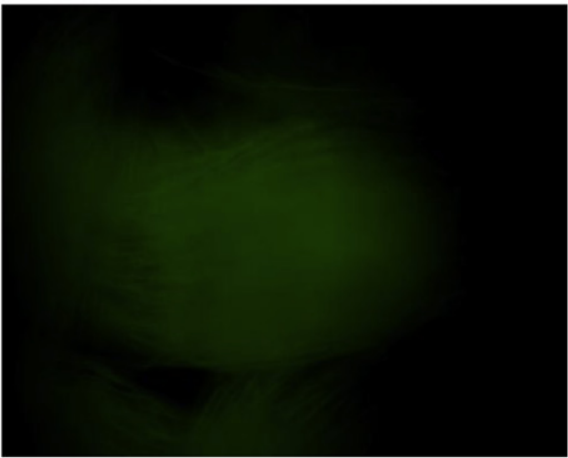

Pristine PET Control
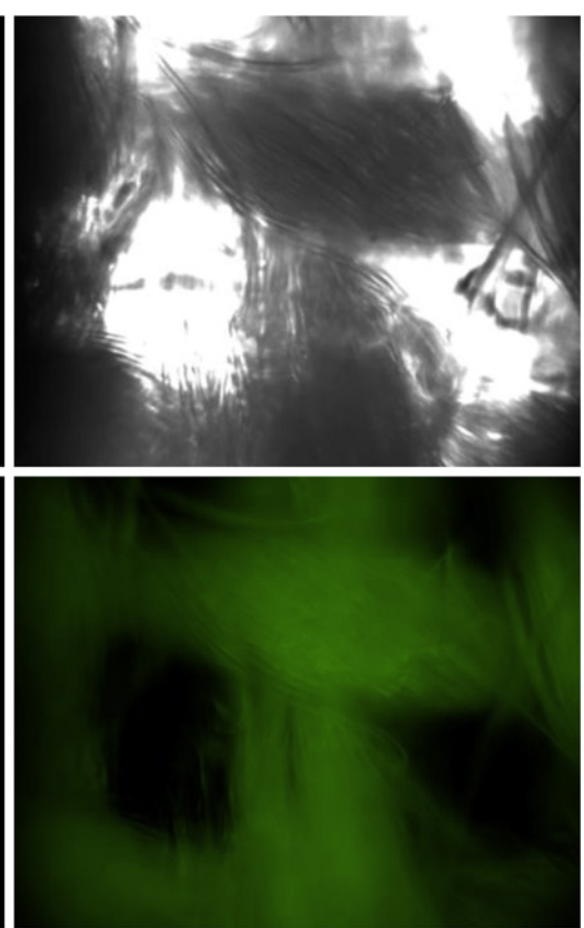

PMBAA-PET Control
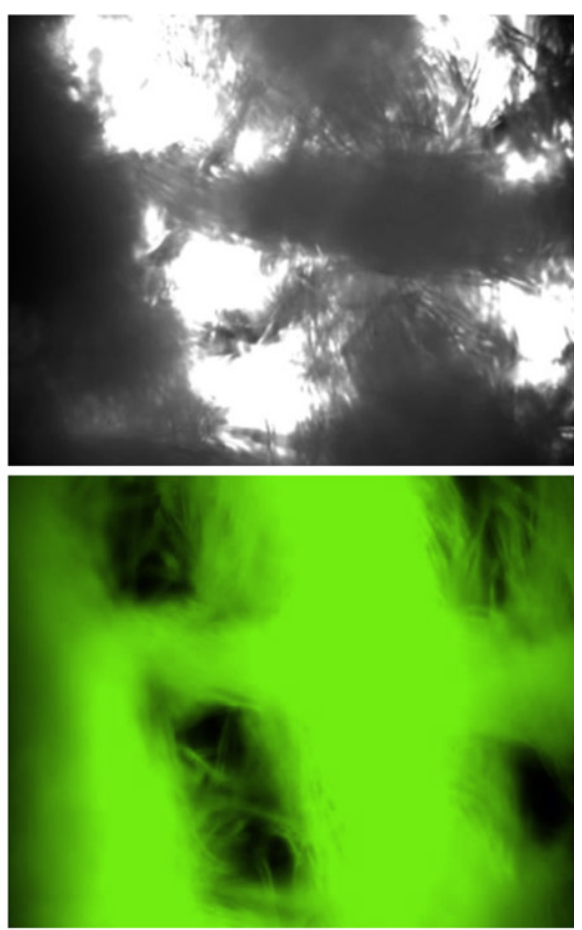

PMBAA-PET-BSA

Fig. 9. Microscopic Observation of PET samples. (a) Optical; (b) Fluorescent images.

\section{Conclusion}

We developed a versatile surface platform presenting alkynyl groups on PET substrates that allows for direct tethering of bioactive moieties via "click" reaction. Significantly, the efficient grafting of hydantoin onto this platform provided an $\mathrm{N}$-halamine-terminated surface that is highly biocidal, thus addressing the key issue of cross contamination of PET-based medical materials in hospital settings. Meanwhile, spatially controlled immobilization of PMBAA on PET can be achieved by using an engraved mask during the UV-initiated photo-polymerization. Following the 2nd step "clicking", arrays/ patterns of biomolecules on the surface of PET could result. We have also shown that upon attaching a $\beta$-azido-CD to the platform, the resultant $\beta$-CD presenting surfaces can specifically capture fluorescent dye coumarin 6 . PET presenting $\beta$-CD could be used to encapsulate certain proteins through a $\beta$-CD-binding peptide tag [38] for improved blood compatibility [37]. Furthermore, BSA tethered with azide tags was successfully immobilized onto the platform. Combined with the region-selective modification method, spatially controlled immobilization of proteins on PET can be achieved for biomedical applications. We expect that this "clickable" platform can be applied for biofunctionalization of a wide range of thermoplastic polymeric substrates, including polypropylene, polyurethane and polyethylene.

\section{Acknowledgments}

The authors are grateful for the financial support from the Natural Sciences and Engineering Research Council of Canada (NSERC) Discovery grant, and the Manitoba Health Research Council (MHRC) Establishment grant. Thank you to Wei He and Abhilash Kulkarni for their help in taking fluorescent pictures.

\section{Appendix. Supplementary data}

Supplementary data associated with this article can be found, in the online version, at doi:10.1016/j.polymer.2011.11.036.

\section{References}

[1] Chu CC, Kizil Z. Surg Gynecol Obstet 1989;168(3):233-8.

[2] Soares B, Guidoin R, Marois Y, Martin L, King M, Laroche G, et al. J Biomed Mater Res 1996;32(3):293-305.

[3] Dimitrievska S, Maire M, Diaz-Quijada GA, Robitaille L, Ajji A, Yahia L, et al. Macromol Biosci 2011;11(4):493-502.

[4] Tweden K, Cameron JD, Razzouk A, Holmberg W, Kelly S. J Heart Valve Dis 1997;6(5):553-61.

[5] Jones AP, Sidhom S, Sefton G. J Foot Ankle Surg 2007;46(6):416-23.

[6] Nissen KE, Stuart BH, Stevens MG, Baker AT. J Appl Polym Sci 2008;107(4): 2394-403.

[7] Boxus M- B. Polym Adv Technol 1996;7:589-98.

[8] Li J, Tan D, Zhang X, Tan H, Ding M, Wan C, et al. Colloids Surf B Biointerfaces 2010;78(2):343-50.

[9] Renaudie L, Narvor CL, Lepleux E, Roger P. Biomacromolecules 2007;8(2): 679-85.

[10] Desait NP, Hubbell JA. Macromolecules 1992;25(1):226-32.

[11] Liu S, Zhao N, Rudenja S. Macromol Chem Phys 2010;211(3):286-96.

[12] Zhao N, Zhanel GG, Liu S. J Appl Polym Sci 2011;120(1):611-22.

[13] Zhao N, Liu S. Eur Polym J 2011;47(8):1654-63.

[14] Liu S, Sun G. Polymer 2008;49(24):5225-32.

[15] Liu S, Sun G. Carbohydr Polym 2008;71(4):614-25.

[16] Kolb HC, Finn MG, Sharpless KB. Angew Chem Int Ed 2001;40(11): 2004-21.

[17] Angell YL, Burgess K. Chem Soc Rev 2007;36(10):1674-89.

[18] Agard NJ, Baskin JM, Prescher JA, Lo A, Bertozzi CR. ACS Chem Biol 2006;1(10): 644-8.

[19] Breed DR, Thibault R, Xie F, Wang Q Hawker CJ, Pine DJ. Langmuir 2009;25(8): 4370-6.

[20] Binder WH, Sachsenhofer R. Macromol Rapid Commun 2007;28(1):15-54.

[21] Binder WH, Sachsenhofer R. Macromol Rapid Commun 2008;29(12-13): 952-81.

[22] Bacchi A, Costa M, Gabriele B, Pelizzi G, Salerno G. J Org Chem 2002;67(13): 4450-7.

[23] ZhangP NgK, Ling CC. Org Biomol Chem 2010;8(1):128-36.

[24] Ashton PR, Gattuso G, Koniger R, Stoddart JF, Williams DJ. J Org Chem 1996; 61(26):9553-5.

[25] Seo TS, Li Z, Ruparel H, Ju J. J Org Chem 2003;68(2):609-12.

[26] Byrtus H, Pawłowski M, Charakchieva-Minol S, Duszyńska B, Mokrosz MJ, Mokrosz JL, et al. Arch Pharm (Weinheim) 1996;329(6):283-90.

[27] Himo F, Lovell T, Hilgraf R, Rostovtsev VV, Noodleman L, Sharpless KB, et al. J Am Chem Soc 2005;127(1):210-6.

[28] Qin GT, Santos C, Zhang W, Li Y, Kumar A, Erasquin UJ, et al. J Am Chem Soc 2010;132(46):16432-41.

[29] Ren XH, Kocer HB, Kou L, Worley SD, Broughton RM, Tzou YM, et al. J Appl Polym Sci 2008;109(5):2756-61. 
[30] Lin J, Winkelmann C, Worley SD, Kim J, Wei C-I, Cho U, et al. J Appl Polym Sci 2002:85(1):177-82.

[31] Liu S, Sun G. J Appl Polym Sci 2008;108(6):3480-6.

[32] Gastmeier P, Stamm-Balderjahn S, Hansen S, Zuschneid I, Sohr D, Behnke M, et al. Am J Infect Control 2006;34(9):603-5.

[33] Ge Z, Xu J, Hu J, Zhang Y, Liu S. Soft Matter 2009;5:3932-9.

[34] Grechin AG, Buschmann H-J, Schollmeyer E. Tex Res J 2007;77:161-4.

[35] Velic D, Knapp M, Köhler G. J Mol Struct 2001;598:49-56.

[36] Wong LS, Khan F, Micklefield J. Chem Rev 2009;109(9):4025-53.

[37] Xu Y, Jin XF, Ping QN, Cheng J, Sun MJ, Cao F, et al. J Control Release 2010; 146(3):299-308.
[38] Dirks AJ, van Berkel SS, Hatzakis NS, Opsteen JA, van Delft FL, Cornelissen JJ, et al. Chem Commun 2005;33:4172-4.

[39] Su TJ, Lu JR, Thomas RK, Cui ZF. J Phys Chem B 1999;103(18):3727-36.

[40] Sigal GB, Mrksich M, Whitesides GM. J Am Chem Soc 1998;120(14):3464-73.

[41] Kim TG, Park TG. Biotechnol Prog 2006;22(14):1108-13.

[42] Wang ZG, Wan LS, Xu ZK. Soft Matter 2009;5(21):4161-8.

[43] Sun XL, Stabler CL, Cazalis CS, Chaikof EL. Bioconjug Chem 2006;17(1):52-7.

[44] Ye P, Xu ZK, Wu J, Innocent C, Seta P. Biomaterials 2006;27(22):4169-76.

[45] Deng HT, Xu ZK, Huang XJ, Wu J, Seta P. Langmuir 2004;20(23):10168-73.

[46] Xie J, MacEwan MR, Ray WZ, Liu W, Siewe DY, Xia Y. ACS NANO 2010;4(9): 5027-36. 